MATEC Web of Conferences 46, 05010 (2016)

DOI: $10.1051 /$ matecconf $/ 20164605010$

(C) Owned by the authors, published by EDP Sciences, 2016

\title{
Fire behaviour of EPS ETICS on concrete or masonry facades
}

\author{
Afipeb, Sipev and Snmi \\ Paris, France
}

\begin{abstract}
In France, fire safety of facades for establishments open to the public has been governed by the Technical Instruction $\mathrm{n}^{\circ} 249$ since 1982; its current version was made regulatory on May $24^{\text {th }}, 2010$. Considering this revision, the Ministry of Interior requested industrials firms to revalidate the fire behaviour of their external insulation systems through testing. AFIPEB, SIPEV and SNMI decided therefore to launch a test campaign.

After a preliminary analysis of Single Burning Item (SBI) data related to EPS ETICS and some full-scale orientation tests, the polyvalent, representative and reliable LEPIR 2 test protocol was implemented. Three EPS ETICS configurations under various renders were tested: one under thick hydraulic renders, another under thin mixed renders and a third under thin organic renders.

These tests were successful. For the first 30 minutes of each test: there was no ignition nor vertical spread of fire to the facade at its second level, there was also no lateral spread of fire along the facade width. Moreover, after 60 minutes, the outer skin above the horizontal line at $5.2 \mathrm{~m}$ was not damaged.

The campaign confirms that EPS ETICS under thin, thick or mixed renders perfectly comply with fire safety regulations. AFIPEB, SIPEV and SNMI wrote a recommendation guide based on approved laboratories assessment. It describes construction solutions limiting fire propagation on a concrete or masonry facade insulated by EPS ETICS. This guide currently supplements IT 249 (2010).
\end{abstract}

\section{CONTEXT}

In France, since 1982, fire safety of facades for establishments open to the public has been governed by the Technical Instruction $n^{\circ} 249$, IT 249 (1982), published by the Ministry of Interior. The current version was made regulatory on May $24^{\text {th }}, 2010$. The fire safety regulation for some residential buildings $\left(3^{\text {rd }}\right.$ and $4^{\text {th }}$ families) also refers to IT 249 (1982). Awaiting the revision of this regulation, the Ministries of Housing and of Interior have recommended the implementation of IT 249 (2010) since September $30^{\text {th }}, 2015$.

IT 249 (2010) deals with different types of facades, systems and materials. External insulation systems on concrete or masonry with openings are addressed in paragraph 5 of which the most important parts for EPS ETICS are the following:

- Paragraph 5.1 describes the requirements on EPS ETICS component characteristics and ancillary protections. Every system satisfying all these requirements can be used without further testing.

This is an Open Access article distributed under the terms of the Creative Commons Attribution License 2.0, which permits unrestricted use, distribution, and reproduction in any medium, provided the original work is properly cited. 
- Paragraph 5.3 applies for EPS ETICS not described in paragraph 5.1. These systems shall be subject to a favourable recommendation delivered by CECMI (Comité d'Etudes et de Classification des Matériaux contre le risque Incendie) about their fire behaviour. This recommendation shall be based on an assessment delivered by an approved laboratory for fire reaction and resistance.

Driven by European and French regulations, in particular Directive 2010/31/EU on Energy Performance of Buildings and the French 2012 Thermal Regulation $\mathrm{n}^{\circ} 2010-1269$, external thermal insulation has grown a lot in France. In this respect, products and systems have evolved to improve thermal performances and to provide a wide choice of finishing. These evolutions led the Ministry of Interior to start the revision of IT 249 (2010). In this context, the Ministry of Interior also requested industrial firms to revalidate the fire behaviour of their external insulation systems through testing.

Thus, since 2010, research and development programmes were implemented by render and insulation manufacturers. These $\mathrm{R} \& \mathrm{D}$ programmes resulted in fire testing campaigns carried out according to LEPIR 2 test protocol, in accordance with IT 249 (2010).

\section{OBJECTIVE OF THE STUDY}

The objective of the study was to confirm the fire behaviour of EPS ETICS under thin or thick renders on concrete or masonry facades.

\section{STAKEHOLDERS}

The test campaign has been jointly carried out by three professional organisations:

- AFIPEB Association Française pour l'Isolation en Polystyrène Expansé dans le Bâtiment.

- SIPEV, Syndicat National des Industries de Peinture, Enduits et Vernis.

- SNMI, Syndicat National des Mortiers Industriels.

The laboratories involved in the study were:

- CREPIM, approved fire reaction laboratory.

- CSTB, Centre Scientifique et Technique du Bâtiment.

- EFECTIS France, approved fire resistance laboratory.

Programme specifications were established by the three professional organisations in collaboration with the laboratories. Before implementation, they were agreed by the Ministry of Interior.

EFECTIS conducted orientation tests leading to select EPS ETICS configurations and ancillary protections. EFECTIS also established the specific characteristics of the renders, based on a statistical analysis of Single Burning Item (SBI) results related to EPS ETICS conducted by CSTB.

The LEPIR 2 tests were carried out by EFECTIS in collaboration with CREPIM.

\section{LEPIR 2 TEST PROTOCOL}

LEPIR 2, Local Expérimental Pour Incendie Réel à 2 niveaux, stands for "Experimental premises for real fire on 2 levels".

This polyvalent, representative and reliable protocol is a proven test in France for over 40 years. It was first published in a regulation dated September $10^{\text {th }}, 1970$ then updated on June $11^{\text {th }}, 2013$ after validation by notified laboratories and the Ministry of Interior. It precisely assesses the fire behaviour of facades enabling to differentiate the various systems and construction provisions.

The method applies to every type of external thermal insulation whatever the nature of the insulating material. It takes into account the whole facade, on two levels, with superimposed openings. It is 
Table 1. Test facility dimensions and characteristics.

\begin{tabular}{|c|c|}
\hline Levels & Dimensions and characteristics \\
\hline Each room $(\mathrm{L} \& \mathrm{~L}+1)$ & $\begin{array}{l}4.30 \mathrm{~m} \text { in length } \\
3 \mathrm{~m} \text { in depth } \\
2.50 \mathrm{~m} \text { high }\end{array}$ \\
\hline Spandrel $(L+2)$ & $\begin{array}{l}\text { About } 1.50 \mathrm{~m} \text { high, from the top } \\
\text { of the openings on the } 2^{\text {nd }} \text { level }\end{array}$ \\
\hline $\begin{array}{l}\text { Total height of the } \\
\text { insulated façade }\end{array}$ & $6.55 \mathrm{~m}$, acroterion included \\
\hline Openings on $1^{\text {st }}$ level (L) & $\begin{array}{l}\text { - Openings: } 1.00 \times 1.50 \mathrm{~m} \\
\text { - Width between the openings: } 1.20 \mathrm{~m} \\
\text { - One window fixed to the bare interior of the structure and } \\
\text { one window fixed to the bare exterior } \\
\text { - PVC frame without glazing }\end{array}$ \\
\hline Openings on $2^{\text {nd }}$ level $(\mathrm{L}+1)$ & $\begin{array}{l}\text { - Openings: } 0.85 \times 1.35 \mathrm{~m} \\
\text { - Width between the openings: } 1.40 \mathrm{~m} \\
\text { - One window fixed to the bare interior of the structure and one } \\
\text { window fixed to the bare exterior (same position as at the first level) } \\
\text { - Complete windows: PVC joinery fitted } \\
\text { with double glazing of type } 6 / 12 / \text { laminated } 44.2 \mathrm{PVB}\end{array}$ \\
\hline
\end{tabular}

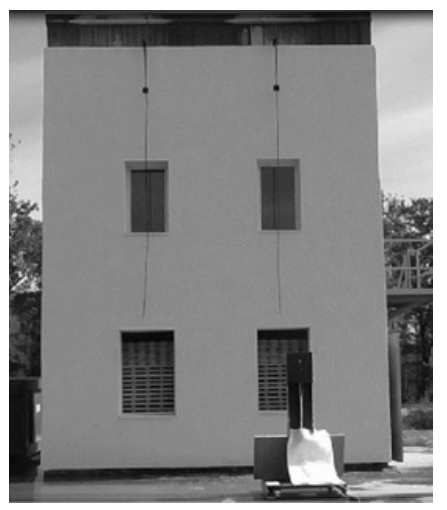

Figure 1. Frontal view of a LEPIR 2 test facility.

therefore representative of real constructions. The fire is fed with two important sources, representing a total load of $600 \mathrm{~kg}$ of calibrated wood.

\section{Test facility}

Tests are carried out on a construction composed of two rooms on two levels, each with two superimposed windows. A spandrel represents level $\mathrm{L}+2$. Side walls are closed. On the rear wall (opposite to the facade), on the ground floor, an adjustable opening is installed to control air input.

\subsection{Characteristics of the fire sources}

The lower level contains two fire sources, each of $1 \times 1 \times 1.8 \mathrm{~m}$, representing a total combustible mass of $600 \mathrm{~kg}$. They are composed of slats with 3 complementary dimensions, made of softwood with a density of $480 \pm 50 \mathrm{~kg} / \mathrm{m}^{3}$. Each fire source is put on a non-combustible base, at $100 \mathrm{~mm}$ from the facade and $200 \mathrm{~mm}$ above the ground. 


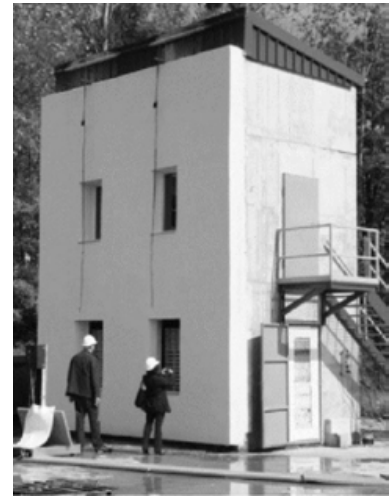

Figure 2. Three quarters view of a LEPIR 2 test facility.

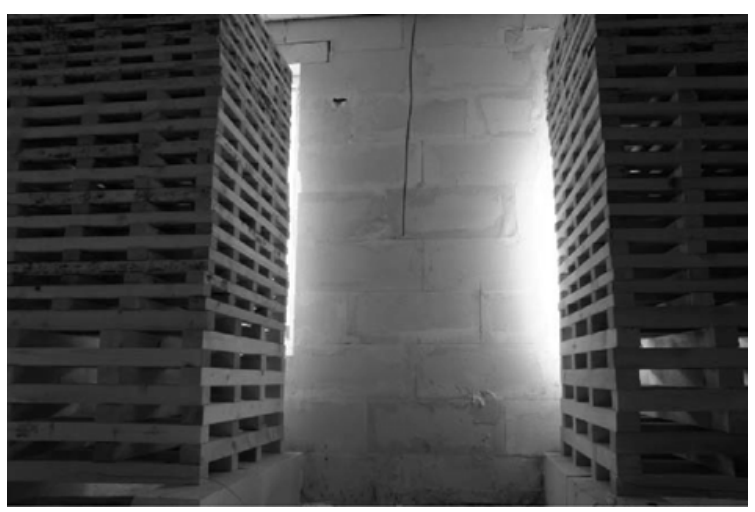

Figure 3. Fire source implantation at the lower level.

\subsection{Climate conditions}

The wind speed is measured during $15 \mathrm{~min}$ at mid-height of openings at the lower level, at $1 \mathrm{~m}$ from the facade. A maximum mean wind speed of $3 \mathrm{~m} / \mathrm{s}$ is allowed.

There must not be any rain nor snow.

\subsection{Equipment of the test facility and observations during the test}

Thermocouples are placed at all points where it is considered necessary to know temperatures reached, in particular in front of the building, at the second level on the facade and inside.

During the test, all incidents such as destructions, ignition of the external render, flame passage between the facade and the floor are registered.

From outside, a video records the entire test. Snapshots of a test are given in the Figs. 4 to 7.

\subsection{Evaluation criteria}

The test is successful under the following conditions.

- For the first 30 minutes of the test:

- No ignition nor vertical spread of fire, for more than 20 seconds, to the facade at $\mathrm{L}+2$.

- No lateral spread of fire along the facade width. 
$2^{\text {nd }}$ International Seminar for Fire Safety of Facades, Lund (Sweden), 2016

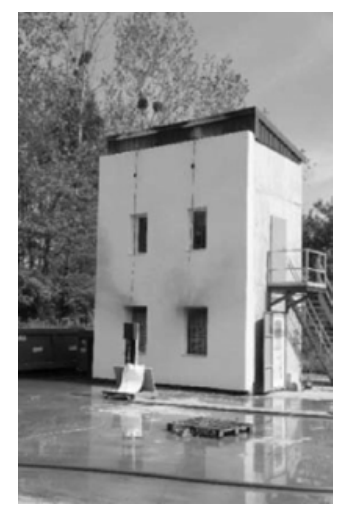

Figure 4. Observation at $1 \mathrm{~min}$.

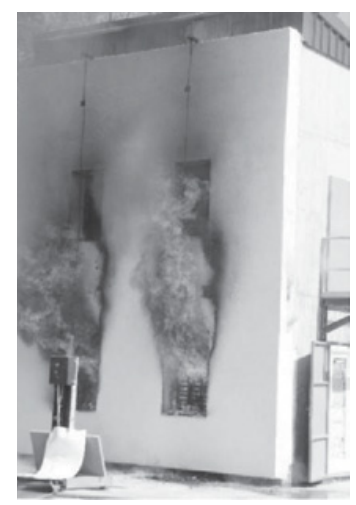

Figure 5. Observation at $10 \mathrm{~min}$.

- For integrated construction systems, at level L+1:

- No spread of flames on the floor through the facade/floor junction.

- No transmission of hot gas $\left(>350^{\circ} \mathrm{C}\right)$ through the facade/floor junction.

- No temperature rise greater than $180^{\circ} \mathrm{C}$ on non-exposed side of floor.

- For ETICS, after 60 minutes, the outer skin above the horizontal line at $5.2 \mathrm{~m}$ must not be damaged. The video of the facade at $\mathrm{L}+2$ can prove that criteria are met.

\subsection{Test report}

At the end of the test, two documents are issued:

- A test report;

- An assessment from the laboratories in form of a conformity report for 5 years.

This test report includes a detailed description with drawings of the element, its components and the fire load. It provides temperature and radiation records, qualitative observations and results. It presents photos taken before, during and after the test. 


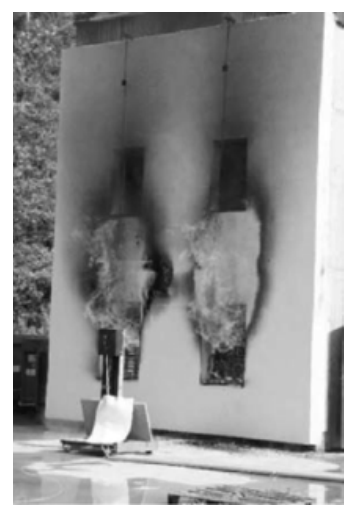

Figure 6. Observation at $20 \mathrm{~min}$.

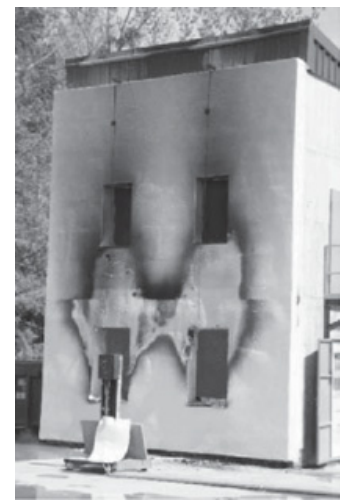

Figure 7. Observation at $30 \mathrm{~min}$.

\section{TEST CAMPAIGN}

\section{Preliminary analysis of SBI data related to EPS ETICS}

The objective of this study was to identify the parameters that may affect reaction to fire of EPS ETICS systems. CSTB analysed about 300 reaction to fire test (SBI) reports, performed between 2005 and 2015. The analysis focused on:

- The Euroclass distribution by nature and chemical composition of the various renders.

- The impact of thickness and flame retardant rate of each render layer on Euroclass.

- The impact of the ratio "flame retardant rate / organic matter rate" on Euroclass.

The study highlighted that the majority of EPS ETICS systems reach Euroclass B or C. It confirmed that the fire behaviour of EPS ETICS under organic render is clearly improved when both basecoat and finishing are flame-proof.

\subsection{LEPIR 2 orientation tests}

Real scale orientation tests were carried out to assess the impact of the system components, as well as the ancillary protections. 


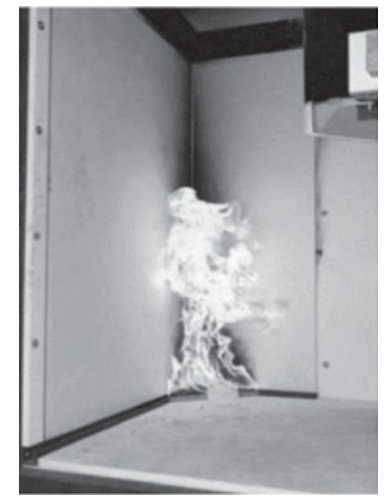

Figure 8. SBI test.

These tests confirmed that horizontal fire barriers at each level fully play their role and no additional protections on openings are needed.

\subsection{Tested configurations}

Considering the conclusion of the analysis of the SBI test results and that of the preliminary test phases, three EPS ETICS configurations under renders were selected:

- EPS ETICS under thick hydraulic renders; total thickness greater than $10 \mathrm{~mm}$.

- EPS ETICS under thin mixed renders (hydraulic basecoat, organic finishing); total thickness lower or equal to $10 \mathrm{~mm}$.

- EPS ETICS under thin organic renders (flame-proof organic basecoat and finishing); total thickness lower or equal to $10 \mathrm{~mm}$.

These configurations fulfil the thermal regulatory requirements and are at least Euroclass $B-s 3, d 0$. They are covered by a valid Document Technique d'Application (DTA) or Avis Technique (AT).

EPS boards, with a maximum density of $20 \mathrm{~kg} / \mathrm{m}^{3}$, are Euroclass E and ACERMI certified. They are bonded on masonry with a hydraulic mortar described in the European Technical Agreement or European Technical Evaluation of the system.

Ancillary protections consist of horizontal fire barriers made of stone wool strips. They are $200 \mathrm{~mm}$ high and have the same thickness as that of EPS boards. These strips run over the whole width of the facade. They are fully bonded on masonry with the same hydraulic mortar and then fixed with dowels every $500 \mathrm{~mm}$.

\section{TEST RESULTS}

Tests were successful and met LEPIR 2 evaluation criteria. EFECTIS and CREPIM consequently issued the following assessment.

- The fire behaviour of EPS ETICS under renders is validated for every EPS thickness lower than those being subject to these tests: $300 \mathrm{~mm}$ for thick renders and $200 \mathrm{~mm}$ for thin renders.

- No minimum nor maximum distance is required between the lintels of the lower level and the sill of the upper level. The facades shall however meet the regulatory requirements for each type of construction. 
Table 2. Components and features of tested configurations.

\begin{tabular}{|c|c|c|c|c|}
\hline \multicolumn{2}{|c|}{ Type of render } & Thick hydraulic & Thin mixed & $\begin{array}{l}\text { Thin organic } \\
\text { flame-proof }\end{array}$ \\
\hline \multicolumn{2}{|c|}{ Bonding mortar } & Hydraulic & Hydraulic & Hydraulic \\
\hline \multirow[t]{3}{*}{ Insulation } & Nature & EPS & EPS & EPS \\
\hline & Thickness & $300 \mathrm{~mm}$ & $200 \mathrm{~mm}$ & $200 \mathrm{~mm}$ \\
\hline & Fixing system & Bonding & Bonding & Bonding \\
\hline \multirow[t]{10}{*}{ Render system } & \multirow[t]{4}{*}{ Reinforced basecoat } & Hydraulic render & Hydraulic render & $\begin{array}{l}\text { Flame-proof } \\
\text { organic render }\end{array}$ \\
\hline & & Thickness $3 \mathrm{~mm}$ & Thickness $3 \mathrm{~mm}$ & Thickness $2 \mathrm{~mm}$ \\
\hline & & \multirow[t]{2}{*}{ TMO 7\% } & \multirow[t]{2}{*}{ TMO 7\% } & TMO $7.5 \%$ \\
\hline & & & & TFR $10 \%$ \\
\hline & \multirow[t]{4}{*}{ Finishing coat } & Hydraulic render & Organic render & Flame-proof organic render \\
\hline & & Thickness $8 \mathrm{~mm}$ & Thickness $2 \mathrm{~mm}$ & Thickness $2 \mathrm{~mm}$ \\
\hline & & TMO $3 \%$ & TMO $10.7 \%$ & TMO $10 \%$ \\
\hline & & & & TFR $8.8 \%$ \\
\hline & \multirow[t]{2}{*}{ Total system } & Thickness $11 \mathrm{~mm}$ & Thickness $5 \mathrm{~mm}$ & Thickness $4 \mathrm{~mm}$ \\
\hline & & FMO $4,5 \%$ & FMO $9 \%$ & FMO $8.5 \%$ \\
\hline \multicolumn{2}{|c|}{ Protection strips } & $\begin{array}{c}\text { Between each level } \\
\text { one at the base }\end{array}$ & $\begin{array}{c}\text { Between each level \& } \\
\text { one at the base }\end{array}$ & $\begin{array}{c}\text { Between each level \& } \\
\text { one at the base }\end{array}$ \\
\hline
\end{tabular}

TMO: Taux de Matière Organique / Organic matter rate.

TFR: Taux d'ignifugeant / Flame retardant rate.

FMO: Fraction Massique Organique / Total organic mass fraction.

Table 3. Render systems and protections: minimum allowed characteristics.

\begin{tabular}{|c|c|c|c|c|}
\hline \multicolumn{2}{|c|}{ Type of render } & Thick hydraulic & Thin mixed & $\begin{array}{r}\text { Thin organic } \\
\text { flame-proof }\end{array}$ \\
\hline \multicolumn{2}{|c|}{ Minimum fire reaction } & B-s3,d0 & B-s3,d0 & B-s3,d0 \\
\hline \multirow[t]{3}{*}{ Minimum thickness } & Reinforced basecoat & - & $3 \mathrm{~mm}$ & $2 \mathrm{~mm}$ flame-proof \\
\hline & Finishing coat & - & - & Flame-proof \\
\hline & Total system & $>10 \mathrm{~mm}$ & $4 \mathrm{~mm}$ & $4 \mathrm{~mm}$ \\
\hline \multirow{3}{*}{$\begin{array}{l}\text { Maximum organic } \\
\text { matter rate }\end{array}$} & Reinforced basecoat & - & $7 \%$ & $\mathrm{R}_{f o} *>1$ \\
\hline & Finishing coat & - & $12 \%$ & $\mathrm{R}_{f o} *>0,9$ \\
\hline & Total system & $5 \%$ & - & $9 \%$ \\
\hline Expanded polystyrene & Maximum thickness & $300 \mathrm{~mm}$ & $200 \mathrm{~mm}$ & $200 \mathrm{~mm}$ \\
\hline \multirow{2}{*}{$\begin{array}{l}\text { Protection strips with } \\
\text { same thickness as EPS }\end{array}$} & Minimum height & $200 \mathrm{~mm}$ & $200 \mathrm{~mm}$ & $200 \mathrm{~mm}$ \\
\hline & Location & $\begin{array}{c}\text { Between each level \& } \\
\text { one at the base }\end{array}$ & $\begin{array}{c}\text { Between each level \& } \\
\text { one at the base }\end{array}$ & $\begin{array}{c}\text { Between each level \& } \\
\text { one at the base }\end{array}$ \\
\hline
\end{tabular}

$* \mathrm{R}_{f o}=(\%$ flame retardant $) /(\%$ organic matter $)$.

- The render systems whose finishing include an organic matter mass fraction lower than $12 \%$ do not contain enough organic load for parietal or lateral spread of fire along the render.

- Expanded polystyrene insulation materials have a CE marking according to EN 13163 standard. They have a density lower or equal to $20 \mathrm{~kg} / \mathrm{m}^{3}$. They shall be flame-proof and at least Euroclass E. The EPS boards supplier shall provide the proof that the raw material producer performs continuous monitoring of the fire proof characteristics (Euroclass D for a conventional $60 \mathrm{~mm}$ thick EPS board).

- Stone wool for protection strips shall have a nominal density greater or equal to $90 \mathrm{~kg} / \mathrm{m}^{3}$, have a CE marking according to EN 13162 standard, be Euroclass A1 and be ACERMI certified or equivalent. 


\section{RECOMMENDATION GUIDE}

AFIPEB, SIPEV and SNMI wrote a recommendation guide based on EFECTIS and CREPIM assessment. This guide practically describes construction solutions intended to limit fire propagation on a concrete or masonry facade insulated by EPS ETICS.

This guide recalls that:

- Facades may have openings or may be blind walls.

- Openings may be equipped with all type, nature and dimension of joinery and can be installed in every position, from the bare interior to the bare exterior of the structure, and without constraints of minimum distance between superimposed openings.

- EPS ETICS can be installed as first insulation or as extra insulation.

The guide also describes:

- EPS ETICS characteristics and related technical justifications.

- EPS insulation boards characteristics, related justifications and installation instructions.

- Render systems composition and specific features.

- Protection strips and related construction provisions.

- Installation instructions around openings.

In addition to EPS ETICS solutions resulting from this campaign, the guide includes technical solutions, previously tested by other actors, for EPS ETICS under thick hydraulic renders, without protection strips, but with reinforced frame protection at openings. This guide supplements IT 249 (2010); it will be available on the Ministry of Interior website (www. interieur .gouv. fr).

\section{CONCLUSION}

The LEPIR 2 test protocol provides a relevant analysis about the fire behaviour of facades thanks to its main assets: test facility dimensions and representativeness, testing procedures and laboratories dual competence in fire reaction and resistance.

Our LEPIR 2 test campaign confirms that EPS ETICS under thin or thick renders perfectly comply with fire safety regulations for buildings. Thus, actors in the construction sector can still design and construct buildings fulfilling the highest thermal requirements, at reasonable cost, while keeping the good fire behaviour of the facades.

Industrial firms positively answered the request from public authorities. EPS ETICS solutions are published in a recommendation guide that will be available on the Ministry of Interior website. This should allow to update IT 249 in the coming future.

\section{Reference}

Internal reports and assessments issued by CREPIM, CSTB and EFECTIS for AFIPEB, SIPEV and SNMI, campaign 2014/2015. 